\title{
OS DESAFIOS DO PESQUISADOR NATIVO: reflexividade, triangulação e questões éticas em pesquisas qualitativas que envolvem o local de trabalho do pesquisador
}

\author{
Marcio Camargo Cunha Filho'
}

\section{Palavras-Chave}

pesquisa qualitativa, pesquisadornativo, vieses de pesquisa, cuidados éticos em pesquisa

\section{SUMÁRIO}

1. Introdução. 2. Armadilhas da pesquisa nativa: reflexões iniciais. 3. Desafios metodológicos do pesquisador nativo e estratégias de superação. 3.1 Reflexividade e estratégias indutivas para minimização de vieses. 3.2 Triangulação entre diferentes fontes de evidência e níveis de análise. 3.3 Seleção de casos e coleta de dados: seus limites e o delineamento da pesquisa. 4. Os desafios éticos da pesquisa no local de trabalho. 4.1 Consentimento esclarecido e anonimato. 4.2 Validação do respondente e pesquisa colaborativa. 4.3 Aprovação do Comitê de Ética em Pesquisa. 5. Conclusões. Referências

1 Doutor em Direito pela Universidade de Brasília, Professor do curso de graduação em Direito do Instituto Brasiliense de Direito Público, Auditor Federal de Finanças e Controle e membro do Comitê de Ética em Pesquisa em Ciências Humanas e Sociais da Universidade de Brasília.

\section{Resumo}

Este artigo explora uma situação frequente, porém pouco debatida em pesquisas jurídicas: os desafios metodológicos e éticos da realização de pesquisas nativas, em que o pesquisador trabalha profissionalmente na instituição que estuda. O objetivo do artigo é explorar as estratégias metodológicas e éticas adotadas na tese de doutorado do autor para superar vieses de pesquisas nativas qualitativas, com a finalidade de contribuir para que futuras pesquisas feitas por insiders obtenham resultados mais confiáveis. $\bigcirc$ artigo demonstra quatro estratégias utilizadas na pesquisa de campo realizada pelo autor em seu ambiente de trabalho: a reflexividade, que envolve a compreensão e reflexão sobre o próprio posicionamento epistemológico e a sua influência na coleta de dados de pesquisa; a triangulação, que diz respeito à coleta de dados em fontes diversas de diferentes níveis de análise; a adoção de critérios para seleção de casos de estudo de forma transparente e que envolva o enfrentamento de casos dissonantes, isto é, casos que não se enquadram na hipótese de pesquisa preliminar do autor; e, por fim, a adoção de cuidados éticos, tais como o anonimato, a validação do respondente e a aprovação de projeto de pesq uisa no Comitê de Ética em Pesquisa. 


\section{THE CHALLENGES OF THE INSIDER RESEARCHER: reflexivity, triangulation and ethical concerns in qualitative research in institutions in which they work}

\section{Marcio Camargo Cunha Filho}

\section{Keywords}

qualitative research/insider research/ research bias/ ethical issues in research

\section{Abstract}

This article explores a frequent albeit rarely discussed issue in judicial research: the challenges of doing qualitative research in which the researcher is an insider, that is, when he investigates the institution in which he works. This article reflects on methodological and ethical strategiesaimed at overcoming biases in native qualitative researches, in order to provide researchers with tools to produce more reliable research in the future. The study explores four research strategies adopted in the author's doctoral thesis: reflexivity, which means reflecting about how one's epistemological position affects the collection of data and its results; triangulation, which is related to collection of data in different sources and different levels of analysis; case selection through transparent criteria that include negative or dissonant cases that contradict the author's initial research hypothesis; and, finally, the adoption of ethical concerns, such as anonymity, respondent validation and the approval of the research project in the Ethics Committee. 


\section{Introdução}

No campo jurídico, são frequentes as situações em que o local de trabalho de um profissional serve de inspiração para a realização de pesquisa acadêmica. Advogados insatisfeitos com a morosidade do Judiciário podem tentar investigar as causas desta lentidão e suas implicações para o devido processo legal; membros do Ministério Público podem realizar pesquisa cujo objetivo seja demonstrar a necessidade de expandir os seus poderes para fins de aumentar a eficácia da persecução criminal; juízes podem se inspirar em casos concretos por eles julgados para defender uma certa interpretação ou aplicação de um princípio jurídico. Em outros casos ainda mais frequentes, juristas militam politicamente com um tema que lhes é caro e que passa também a ser investigados academicamente. Nestes e em outros casos, muitos dos profissionais-pesquisadores e dos militantes-pesquisadores se deparam com a crítica de que sua pesquisa tem um teor instrumental, isto é, serve tão-somente para legitimar certas visões ou para fortalecer a carreira profissional do autor ou da autora, desvirtuando a prática acadêmica e retirando-Ihe cientificidade. Este artigo tem por objetivo refletir sobre estratégias metodológicas e éticas a que o pesquisador deve atentar se decidir escrever sobre um tema ou uma instituição com a qual possui vinculação profissional prévia. As reflexões partem e se apoiam na minha experiência pessoal como pesquisador nativo: durante meu doutorado acadêmi$\mathrm{co}$, realizei pesquisa sobre o processo de tomada de decisões em recursos de acesso à informação (Cunha Filho, 2019), tarefa que desempenhei profissionalmente como auditor da Ouvidoria-Geral da União da Controladoria-Geral da União.

Será que, no caso de acumulação de papeis, há uma instrumentalização indevida da pesquisa acadêmica, que pode acabar tendo como propósito principal ou único legitimar ou ratificar conclusões ou argumentos que servem de suporte para a prática profissional em questão? É possível cogitar que o pesquisador nativo seja necessariamente enviesado, ou seja, sua perspectiva e sua abordagem estão necessariamente condenadas a analisar a sua própria prática laboral de maneira positiva ou elogiosa, rompendo com o ceticismo e o espírito crítico que são tão essenciais à ciência? No presente artigo argumentarei que o ambiente profissional pode ser uma fonte legítima de inspiração e de obtenção de dados de pesquisa, podendo inclusive ser um fator facilitador para acesso a dados e para a contextualização da importância ou significado da pesquisa acadêmica; entretanto, exercer este duplo papel impõe desafios que o pesquisador nativo precisa enfrentar explicitamente. Em suma, o artigo tenta responder a seguinte pergunta: como se assegurar que uma pesquisa nativa chegue a conclusões cientificamente confiáveis, considerando a prévia inserção e atuação do pesquisador no campo profissional, bem como a existência prévia de posicionamentos e argumentos por parte deste profissional-pesquisador?

Minhas respostas se baseiam nas estratégias por mim adotadas em minha tese de doutorado para superar os desafios impostos pela duplicidade de papeis de pesquisador acadêmico na área de transparência pública e profissional atuante como auditor da Controladoria-Geral da União. Ainda que se baseiem em uma experiência particular, estas estratégias metodológicas e cuidados 
éticos podem ser replicados por outros pesquisadores nativos ou militantes. As estratégias metodológicas que discutirei são a reflexividade, a triangulação entre diferentes fontes de informação e a adoção de critérios rigorosos para seleção de casos de análise. A análise de como apliquei essas estratégicas metodológicas é realizada nos itens 3.1, 3.2 e 3.3, respectivamente. No item 4, me debruço com mais detalhes sobre os desafios éticos impostos ao pesquisador nativo - a problemática é tratada em item separado devido à relevância e urgência de se pensar em implicações éticas em pesquisas jurídicas, tema que raramente se faz presente neste campo. Na próxima seção, contextualizo o tema que pesquisei, o ambiente profissional em que estava inserido e os princípios e preocupações principais que me nortearam como pesquisador nativo.

\section{Armadilhas da pesquisa nativa: refle- xões iniciais}

A minha ideia de escrever uma tese de doutorado sobre transparência pública surgiu em novembro de 2012, quando tomei posse como auditor federal da Controladoria-Geral da União (CGU) e fui lotado na Ouvidoria-Geral da União (OGU). Àquela época, a CGU acabara de ganhar, por meio da Lei $n$. 12.527/11 (a Lei de Acesso à Informação, ou simplesmente "LAI"), a prerrogativa de julgar recursos contra decisões dos órgãos do executivo federal que negavam acesso a informações públicas. Logo após a minha posse, comecei a atuar como assessor do então Ouvidor-Geral da União, que foi designado como a principal autoridade julgadora destes recursos. Como a LAl acabara de entrar em vigor, muitos de seus significados, conceitos e problemáticas se encontravam em aberto. Isso me incentivou a participar das discussões que a equipe realizava sobre o tema e a estudá-lo em maior profundidade - ainda que não me dedicasse a ele com exclusividade, como outros colegas o fizeram. Naquele momento, eu acreditava que a novidade legislativa deveria ser utilizada para promover uma abertura radical dos documentos públicos. Afinal, tratava-se de um momento único e irrepetível, um ponto de inflexão na história da administração pública brasileira semelhante ao que os cientistas políticos denominam de "big bang" (Taylor, 2018), ou seja, um momento de profunda reconfiguração de práticas, rotinas e princípios. Naquele contexto, eu acreditava estar em uma posição privilegiada para realizar uma pesquisa acadêmica: afinal, estava atuando no órgão mais importante de implementação da LAl, e podia assim acompanhar de perto suas possibilidades e desafios, ao mesmo tempo me aproximava do curso de doutorado em direito da UnB, em um ambiente em que podia tentar compreender o significado do meu trabalho para o contexto democrático que o Brasil vivia à época.

Em 2015 ingressei no doutorado e comecei a efetivamente pesquisar o tema. Naquele momento, imaginava que uma tese de doutorado seria algo que apenas eu poderia conduzir em alto nível, devido à minha dupla condição de pesquisador-servidor público. No entanto, naquele momento não estava plenamente ciente dos desafios envolvidos na realização de pesquisa no próprio ambiente de trabalho. Em especial, superestimei a validade e confiabilidade dos juízos e opiniões que formara sobre o tema antes de começar a pesquisa-lo. Por estar trabalhando na CGU e próximo à área de acesso à informação, imaginava que tudo sabia sobre o tema e que todas as pergun- 
tas e respostas relevantes já estavam na minha mente. Estava seguro de que conhecia a plenitude do processo decisório do meu órgão em matéria de acesso à informação e estava convicto de que conhecia os fatores que produziriam variações de resultados de recursos de acesso à informação. Este é um erro comum de pesquisadores nativos, que costumam pensar que a inserção profissional em um determinado campo thes dá, por si só, todos os elementos para realizar uma pesquisa acadêmica com rigor e qualidade. Aos poucos, fui percebendo que minhas visões iniciais estavam dominadas por uma heurística do afeto, uma forma de pensar que "simplifica nossas vidas criando um mundo que é muito mais ordenado do que a realidade" (Kahneman, 2012, p. 178).

Hoje acredito que, apesar da minha proximidade, no início do meu doutorado conhecia o tema que me propunha a pesquisar de maneira muito parcial e enviesada. Minhas certezas sobre a implementação da LAI eram opiniões formadas por juízos rápidos, irrefletidos e frequentemente superficiais. Estas certezas iniciais não são mudadas com facilidade, por causa do fenômeno da assimilação enviesada de informações, que faz com que "crenças estabelecidas podem ser notavelmente difíceis de mudar, mesmo quando as evidências da crença inicial são completamente desacreditadas" (Munro \& Ditto, 1997, p. 636). Nossas pré-convicções tendem a filtrar e enviesar o modo com que interpretamos evidências científicas, criando um enviesamento que fortalece estas visões prévias (Munro \& Ditto. 1997, p. 638). Assim, do ponto de vista metodológico, o pesquisador nativo precisa encarar a realidade de que o processamento de informações de valor científico se faz de forma enviesada (Munro \& Ditto, 1997), o que traz consequências consideráveis, especialmente para pesquisas qualitativas.

Em pesquisas convencionais, uma das principais tarefas do pesquisador é se aproximar de seu objeto de estudo para compreendê-lo melhor. Pesquisar uma instituição com a qual se possui um vínculo profissional prévio envolve um caminho reverso: se afastar de seu ambiente original para estranhar interpretações sobre o significado de atos, palavras e comportamentos que antes eram vistos como normais ou naturais (Alvesson, 2003). O pesquisador nesse caso é uma espécie de "fugitivo" que se afasta de seu ambiente natural para ganhar perspectiva e somente depois retornar e analisá-lo com outros olhos (Alvesson, 2003; Nielsen \& Repstad, 1993). No meu caso, meu doutorado envolveu um grande esforço de relativizar e reavaliar minhas noções pré-concebidas sobre a construção da política de transparência no país. Um requisito imprescindível para qualquer pesquisa nativa é reduzir ou minimizar os próprios preconceitos e opiniões antecipadas acerca do objeto de pesquisa. É necessária, portanto, uma "estratégia crítica de desfamiliarização", que envolve romper com o que é tido como senso comum, familiar e natural (Marcus \& Fischer, 1986), ou converter o que é tido por evidente em exótico e questionar o seu significado (Alvesson, 2003). Não é uma tarefa fácil, porque afinal a nossa primeira impressão sobre algo geralmente molda nossas atitudes e posições posteriores - é o que os psicólogos chamam de efeito halo (Kahneman, 2012).

A tentativa de superar conclusões precipitadas precisa ser sempre acompanhada de uma tarefa adicional que me parece essencial a todo pesquisador nativo: a de manter uma postura crítica, questionar certezas e 
"verdades absolutas", falar sobre assuntos que causam desconforto; em suma, "representar todas as pessoas e todos os assuntos que são sistematicamente esquecidos ou varridos para debaixo do tapete" (Said, 2005 , p. 28). Afinal, o que faz do intelectual alguém comprometido com a justiça e o equilíbrio social é a sua disposição de confrontar o poder (Said, 2005). Sobretudo quando estudamos a nós mesmos, nossas pesquisas não podem ser embelezadas ou acríticas somente pelo fato de sermos um insider (Alvesson, 2003), especialmente em um momento histórico em que as pesquisas acadêmicas se encontram em risco de serem cooptadas por interesses econômicos ou políticos (Bourdieu, 2004). No caso da minha pesquisa, a minha única forma de contribuir para o avanço das políticas estatais de transparência seria manter uma postura crítica e questionadora das narrativas oficiais do Estado. A única forma com que o pesquisador nativo pode efetivamente contribuir com o avanço do debate é mantendo postura crítica e construindo fissuras, e não simplesmente ratificando consensos existentes ou confirmando visões consolidadas sobre seu objeto de pesquisa. Ao mesmo tempo, contudo, o insider não pode deixar de reconhecer a importância e o esforço de seu próprio trabalho e de seus pares, que muitas vezes acreditam genuinamente na relevância de seu trabalho e na correção absoluta de seus atos. Por meio da descrição e análise das estratégias por mim adotadas como pesquisador nativo, espero contribuir nas próximas páginas para que outros pesquisadores reflitam sobre os desafios metodológicos de refletir sobre o próprio ambiente de trabalho, superando as armadilhas inerentes a qualquer tipo de pesquisa nativa.

\section{Desafios metodológicos do pesquisa- dor nativo e estratégias de superação}

A pesquisa no meu ambiente de trabalho teve como objetivo geral analisar os processos de tomada de decisões em recursos administrativos de acesso à informação, tarefa que eu desempenhara como auditor da CGU. Investigar este tema demandou uma abordagem qualitativa, mais especificamente um estudo de caso, que pode ser definido como "estudo intensivo de uma única unidade de análise com o propósito de entender uma classe mais ampla de unidades semelhantes" (Gerring, 2009, p. 342), ou como o estudo de uma "classe de eventos de um fenômeno de interesse científico (...) que o pesquisador opta por estudar com o objetivo de desenvolver uma teoria (ou um conhecimento genérico) acerca das causas de semelhanças ou diferenças dentre instâncias da classe de eventos" (George \& Bennet, 2005, pp. 17-18). A realização de pesquisa qualitativa pode se tornar enviesada porque a seleção de casos não é feita aleatoriamente, mas sim com base em resultados conhecidos, e as possibilidades de generalização são limitadas, sendo principalmente analíticas, e não estatísticas (Yin, 2016). Para fazer frente aos desafios impostos pela pesquisa qualitativa no próprio trabalho, segui os seguintes passos: (i) adoção de uma postura reflexiva, que explorou de maneira aprofundada a minha relação com o objeto de pesquisa, e a consequente adoção de estratégias que reduziram o meu enviesamento como pesquisador e principal instrumento de pesquisa; (ii) triangulação de fontes diversificadas de evidência e de diferentes níveis de análise; (iii) descrição transparente e detalhada do procedimento de seleção de casos, bem como exposição da limitação do universo de dados disponí- 
veis, além da apresentação do delineamento lógico da pesquisa. A adoção de cuidados éticos é tema destacado em seção apartada, não apenas por constituir tema de especial relevância para pesquisas nativas, mas também porque se trata de tema amplamente ignorado pelo campo jurídico.

\subsection{Reflexividade e estratégias indutivas para minimização de vieses}

Reflexividade é "o esforço por meio do qual as ciências sociais, tomando a si própria como objeto, usam suas próprias armas para fiscalizar a si mesma", o que é uma "forma particularmente efetiva de aumentar as chances de chegar à verdade por meio do aumento de controles cruzados e da utilização de princípios de uma técnica crítica que torna possível acompanhar de perto os fatores que podem enviesar uma pesquisa" (Bourdieu, 2004, p. 89). Mais do que um "olhar retrospectivo complacente" (Bourdieu, 2004), reflexividade é a atividade de se submeter a uma autocrítica proposital e constante; é um ato de introspecção que permite ao pesquisador reavaliar e autocriticar as suas concepções e crenças prévias a respeito do objeto de pesquisa, levar em conta a sua relação com os entrevistados da pesquisa, rejeitar aparências em favor de formas mais aprofundadas de formação de certeza (Lynch, 2000). A reflexividade permite ao escritor objetificar seu ponto de vista, superar a ilusão de que ele é absoluto e compreender que a verdade sempre será objeto de infindáveis disputas (Bourdieu, 2004). Permite, em suma, que o pesquisador tenha uma atitude científica, definida como aquela em que conclusões são tomadas com base em evidências e em teorias que as explicam, e não com base em ideo- logias, impressões e intuições prévias (Mclntyre, 2019).

Sendo pesquisador nativo o principal instrumento de pesquisa, seus sistemas de valores e processos próprios de pensamento o conduzem a analisar certos dados e a deixar de analisar outros, ao mesmo tempo que o dirigem a certas possibilidades interpretativas e excluem outras. A parcialidade, a seletividade da análise e a falta de neutralidade são, na verdade, inerentes a qualquer pesquisa em ciência social (Becker, 1967), mas no caso do pesquisador nativo os riscos de enviesamento são aumentados devido à sua condição prévia de membro da instituição estudada nesta pesquisa. As dificuldades de pesquisar o próprio ambiente de trabalho são tão significativas que alguns autores a desaconselham expressamente, afirmando que este duplo papel pode afetar negativamente tanto a pesquisa quanto a trajetória profissional do pesquisador. $O$ argumento destes autores é que o insider não pode realizar uma pesquisa com o necessário rigor por estar envolvido demais com as práticas organizacionais, não possuindo o distanciamento e condições mínimas de objetividade para realizar uma pesquisa válida (Anderson \& Herr, 1999). Alvesson (2003) demonstra preocupação com as expectativas de lealdade que uma instituição pode depositar no insider, induzindo-o, direta ou indiretamente, a adotar postura ideologicamente subordinada aos objetivos institucionais. Morse (1998) afirma que os papéis de pesquisador e membro de uma organização são "incompatíveis" e que sua união é "insustentável".

Brannick e Coghlan (2005; 2007) contestam esse argumento. Para eles, o pesquisador nativo enfrenta problemas particulares, porém pode realizar pesquisa válida e com rigor se mantiver elevado o seu nível de refle- 
xividade, ou seja, se explorar a complexidade de sua relação com o objeto de pesquisa, compreender e elucidar suas limitações e adotar estratégias para superá-las, de forma a assegurar que a pesquisa represente uma visão aprofundada do fenômeno estudado, e não uma imposição da visão de mundo que o autor já tinha previamente. Caso essas estratégias sejam bem-sucedidas, é possível afirmar que o pesquisador nativo está em posição de vantagem em relação a pesquisadores externos, porque possui de início a expertise necessária para a compreensão do problema de pesquisa. Por exemplo, o pesquisador nativo tem familiaridade com os jargões, tabus, objetivos da organização, seus dados primários e personagens relevantes. Afinal, "o que é mais importante para o desenvolvimento de teoria e conhecimento científico não é a fonte de teorias ou ideias, mas sim o processo por meio do qual estas ideias são testadas" (Brannick \& Coghlan, 2007, p. 64). Kenneally (2013) concorda que, apesar dos vários desafios envolvidos em pesquisar a instituição de que faz parte, o insider encontra-se em uma posição privilegiada para realizar um estudo aprofundado e único sobre sua instituição.

Já os riscos relacionados à posição do nativo se dividem, segundo Brannick e Coghlan (2005; 2007) em três grandes grupos: em primeiro lugar, ainda que seja fácil ao nativo obter dados primários da organização pesquisada, obter dados secundários pode ser mais difícil porque o pesquisador nativo pode ser considerado por seus pares como alguém que está infringindo o ethos da instituição por realizar uma pesquisa que não necessariamente se alinha à sua doutrina oficial. Nos casos mais graves ele pode até ser visto como uma espécie de espião ou de traidor. Isso pode fazer com que os mem- bros da organização se mostrem reticentes ou seletivos ao compartilhar informações. Nesses casos, a pesquisa, cujo objetivo central é o rigor teórico e o rigor da análise de dados, pode se chocar com valores vistos pelos membros da instituição como mais relevantes, como a proteção do legado institucional. Em segundo lugar, o pesquisador nativo inevitavelmente possui pré-compreensões sobre o fenômeno estudado, o que pode fazer com que ele se feche em seus conhecimentos prévios e não ouça ou interaja adequadamente com os dados e informações que emergem ao longo da pesquisa (esse ponto é também enfatizado por Alvesson, 2003). Em terceiro lugar, o pesquisador nativo pode enfrentar uma espécie de "crise existencial", pois pode haver conflitos de interesses entre suas múltiplas personalidades, especialmente o seu "eu" pesquisador e o seu "eu" servidor público, tornando difícil sustentar relações de lealdade e expectativas de comportamento. Por exemplo, se, durante a realização de entrevistas, um colega relatar ao pesquisador-colega a ocorrência de prática de um ato ilícito, a sua condição de servidor público em tese o obrigaria a relatar a referida ilegalidade a seus superiores, porém a sua posição de pesquisador o proíbe de fazê-lo, pelo dever de assegurar proteção às fontes.

É preciso adotar medidas destinadas a minimizar estes riscos durante toda a elaboração da pesquisa nativa. A mais importante destas medidas é permitir que eventos descobertos durante a pesquisa guiem a formação de conceitos e hipóteses, e não o inverso (Yin, 2016). A abordagem de pesquisa deve ser, portanto, interativa: as questões de pesquisa, hipóteses, argumentos e preocupações com a validade devem interagir constantemente, ao longo de todo o 
processo (Maxwell, 2013). Adotar uma postura interativa significa que o pesquisador deve tentar suspender ao máximo todas as pré-concepções durante a coleta de dados, em especial na realização de entrevistas, já impressões iniciais sobre fenômenos tendem a moldar o significado dos fatos que analisamos posteriormente (Kahneman, 2012). Assim, na realização de entrevistas, por exemplo, o pesquisador nativo deve fazer perguntas abertas em vez de perguntas diretivas, dando ao entrevistado liberdade para responder o que queira e como queira. Deve também incorporar os achados das entrevistas inicias nas próximas, isto é, deve ativamente modificar suas perguntas, seus pontos de preocupação e a forma de conduzir o diálogo com os colegas pesquisados.

Essa postura nas entrevistas é importante porque a pesquisa no próprio ambiente de trabalho não apenas traz riscos relacionados ao enviesamento prévio do próprio pesquisador, mas pode influenciar também a participação das pessoas na pesquisa, ou seja, pode causar reatividade (Maxwell, 2013). Dito de outra forma, as relações profissionais prévias do pesquisador com os participantes de pesquisa afetam não somente as suas próprias lentes de análise, mas podem influenciar também a reação dos participantes à sua presença (Brennick \& Coghlen, 2007; Kara \& Phillips, 2008). Por exemplo, na minha tese de doutorado, alguns dos participantes já conheciam minhas posições prévias sobre o objeto de pesquisa. Alguns deles podem ter se sentido obrigados a apenas mostrar argumentos contrários aos meus, se de mim discordavam, enquanto outros podem apenas ter desejado me agradar e dizer coisas com as quais eles sabem ou imaginam que eu concordaria. Além disso, a adoção de postura reflexiva significa travar uma relação com os participantes de pesquisa que não se resume a uma simples coleta de dados, mas que se aproxime mais a um diálogo franco e honesto, conforme analiso mais na seção de cuidados éticos.

A implicação mais relevante da reflexividade é a rejeição de uma visão linear do problema estudado. O pesquisador nativo, portanto, tem o dever de apresentar todas as nuances e até mesmo contradições entre as abordagens possíveis do seu objeto de pesquisatrabalho. Novamente recorro ao exemplo da minha pesquisa para aprofundar essa questão. Na minha tese, a preocupação central girava em torno da importância e dos impactos da política de transparência no governo federal. Embora partisse da hipótese inicial de que a transparência não necessariamente gerava consequências positivas para a governança, me preocupei durante toda a tese em apresentar e contrapor argumentos contrários à minha hipótese inicial. Mesmo na revisão de literatura, busquei contrapor e testar os argumentos que afirmavam que a transparência é elemento-chave para regimes democráticos com aqueles mais céticos, que afirmavam que a transparência gera poucos impactos na ação estatal (para um maior aprofundamento neste assunto, veja-se Cunha Filho, 2018). Para tentar compreender a origem e a fundamentação destas abordagens contrapostas, me utilizei de dois modelos ou lentes de análise contrapostas. Percebi que os entusiastas da transparência adotavam um modelo objetivo, focado sobretudo nas normas formais de tomada de decisão, enquanto os mais céticos adotavam um modelo subjetivista, em que o foco recaiu sobre a atuação dos atores do sistema e como eles criam regras informais de decisão. O primeiro modelo pensava o sistema decisório de 
recursos de informação como algo dado e externo à ação humana e que a influência ou até a determina, enquanto que o segundo refletiu sobre a existência de uma margem de autonomia dos agentes públicos e sua possibilidade de influenciar resultados no contexto de uma instituição, apresentando o direito não como algo estático ou dado no tempo, mas como uma permanente construção de significados que pode fugir da estrutura formal. Em uma pesquisa jurídica tradicional, seria costumeiro ignorar abordagens contrapostas e selecionar para análise apenas o arcabouço teórico que conduz aos resultados a que sempre se quis chegar. Na minha pesquisa, contudo, tentei aplicar ambos os modelos ao caso brasileiro. O resultado foi uma análise final do sistema de transparência que partia de pressupostos diferentes e chegava a conclusões opostas sobre a efetividade as implicações da política de transparência do governo federal. Resumindo a discussão e enfatizando o ponto principal, acredito que a ausência de certezas absolutas sobre o objeto de estudo não pode, nas pesquisas nativas, ser vista como uma fraqueza acadêmica; pelo contrário, uma verdadeira atitude científica significa compreender que qualquer modelo analítico captura apenas parte de um fenômeno, e que qualquer conclusão é provisória e pode ser superado por pesquisas superiores (Mclntyre, 2019). O que cabe à pesquisa acadêmica, portanto, é tentar se aproximar ao máximo possível da verdade, sempre dando margem à falsificabilidade das constatações.

A pesquisa reflexiva precisa, acima de tudo, compreender que não há uma dicotomia ou uma oposição linear entre abordagens contrapostas, mas sim um constante atrito ou tensão entre elas, ou uma relação complexa de mútua implicação e interação entre elas. Incorporar à pesquisa modelos de análise contrapostos é relevante porque uma pesquisa nativa e qualitativa deve compreender o fenômeno estudado de maneira complexa, mesmo que às custas da coerência ou da linearidade da explicação proposta. Por outras palavras, os modelos contrapostos funcionam como distintas lentes de análise: cada uma amplia ou enfatiza certos aspectos, negligenciando ou borrando outros, e a combinação de ambas pode trazer insights mais aprofundados e completos (Alisson \& Zelikow, 1999). Eles são diferentes formas de agrupar e recortar dados que partem de diferentes pontos de partida acerca do que importa para a análise do fenômeno estudado e criam diferentes formas de produzir respostas. Mais do que isso, modelos teóricos distintos produzem também diferentes perguntas, podendo portanto ser complementares: no caso da minha tese de doutorado, a análise das regras formais do sistema de transparência foi complementada por uma análise do contexto organizacional e político em que estas regras são aplicadas e em como o Direito se modifica por meio da agência que os servidores públicos possuem para criar rotinas que constituem um sistema informal de tomada de decisões, que atua às margens do sistema formal.

\subsection{Triangulação entre diferentes fontes de evidência e níveis de análise}

Tradicionalmente, pesquisas jurídicas tendem a se focar na análise de leis ou decisões judiciais sem atentar para o fato de que o processo de construção destas leis e decisões importa para compreender como elas serão mobilizadas no futuro. O contexto e os percursos que levam a aprovações de leis 
ou a tomada de decisões condicionam e direcionam futuras decisões sobre um determinado assunto. Mais do que isso, quando analisamos uma lei ou uma decisão como produtos únicos e acabados do Direito, perdemos oportunidades de fazer explicações ou previsões sobre seu uso futuro. Afinal, antes de ser algo dado ou que está posto, - Direito é uma contínua construção de significados históricos que nunca se acaba plenamente, encontrando-se em constante transformação e ruptura, pois "o compromisso envolvendo a escrita de regras (...) irá frequentemente gerar estruturas que se descolam da lógica inicial imaginada pelos escritores dessas regras, abrindo assim oportunidades para que futuros operacionalizadores da lei mudem seus significados originais" (Jacobs, 2010).

O pesquisador nativo, por possuir uma inserção nas rotinas e procedimentos de seu objeto de pesquisa, tem a oportunidade de avançar para além das pesquisas jurídicas formais ou normativas. Ele pode ou até mesmo tem a responsabilidade de analisar o processo de produção e uso de ferramentas jurídicas de forma minuciada, de uma maneira que dificilmente é captada por observadores externos. Esse olhar minuciado só pode ser obtido por meio da triangulação de fontes diversas e independentes de pesquisa. Na minha pesquisa de doutorado, as principais fontes de evidências analisadas na pesquisa foram (i) o conjunto de leis e atos infra legais que estruturam o subsistema de acesso à informação no Brasil; (ii) as decisões de casos concretos que decidiram controvérsias relacionadas à LAl; (iii) entrevistas semiestruturadas com agentes públicos que participaram do processo decisório destes recursos; (iv) e documentos oficiais dos órgãos estudados obtidos por meio da
Lei de Acesso à Informação. Subsidiariamente, também foram analisadas reportagens jornalísticas para avaliar quais decisões tiveram repercussão para fora do ambiente administrativo. A triangulação permitiu a coleta de dados por meio de fontes independentes, ou seja, que não se comunicavam entre si (Kahneman, 2012), ainda que no caso da pesquisa a que me refiro elas não tenham sido absolutamente independentes. Estas quatro fontes independentes de pesquisa podem servir de modelo para outras pesquisas que envolvam o próprio ambiente de trabalho. A importância de expandir as fontes de pesquisa nos trabalhos nativos aumenta devido ao fato de que pesquisas nativas precisam contrapor os riscos de enviesamento analisando o maior número de fontes possíveis. A incorporação de múltiplas fontes pode contrapor a subjetividade do pesquisador nativo com a objetividade das evidências independentes.

A análise das normas que estruturam o sistema formal de tomada de decisões precisa superar a mera descrição de preceitos legais ou infra legais, atividade que já é realizada em exaustão por manuais jurídicos, não sendo necessário reproduzi-la em pesquisas científicas. O pesquisador nativo está em um contexto privilegiado para realizar uma reflexão aprofundada sobre o significado das normas no contexto de operacionalização do subsistema jurídico em que está inserido. Análises jurídicas costumam dar muita atenção para Leis ou dispositivos constitucionais, sem atentar para o fato de que decisões administrativas muitas vezes se embasam mais em atos normativos infra legais do que em atos normativos superiores. A multiplicidade de fontes normativas é uma realidade que não pode ser ignorada, embora frequentemente o seja pela litera- 
tura especializada. Por mais que em princípio todos os atos normativos sejam públicos, a grande quantidade de normas no ordenamento faz com que muitas vezes pesquisadores externos tenham dificuldades de acesso a portarias, instruções normativas e outros documentos internos de um órgão que podem ser fundamentais para compreender um fenômeno jurídico; o pesquisador nativo não apenas tem acesso facilitado a esses normativos, mas está em posição especial para compreender seu significado e a sua operacionalização.

Com relação à seleção dos casos para análise de tese, eu propunha, na minha tese de doutorado, uma análise qualitativa de um número pequeno de casos concretos. Um dos dilemas que enfrentei foi se poderia analisar academicamente decisões elaboradas por mim - se eu o fizesse, a possibilidade de enviesamento ou de análise embelezada do caso aumentaria. Para evitar os problemas de seleção de caso, realizei previamente uma análise longitudinal de decisões dos principais órgãos que decidem recursos de informação. Durante esta parte da pesquisa, eu busquei identificar as decisões que tratavam de certos assuntos que me pareceram relevantes a partir da revisão bibliográfica prévia e da análise legislativa. A partir daí, identifiquei os leading cases ou decisões inovadoras (que produziam um entendimento novo) de decisões repetitivas (que apenas reiteravam um posicionamento anterior). O importante nesse ponto é que o pesquisador nativo, ou o pesquisador qualitativo em geral, precisa adotar critérios transparentes de seleção de casos, de modo a evitar ao máximo escolher apenas casos que comprovem suas percepções prévias. Aprofundarei esse ponto na próxima seção.

Já as entrevistas realizadas permitiram cap- tar as percepções e opiniões dos agentes públicos que participam de forma direta desses momentos históricos. As entrevistas podem revelar fatos e interpretações sobre um processo decisório estatal que jamais são captados por meio da análise exclusiva de decisões ou de atos normativos. Na minha tese de doutorado, planejei algumas perguntas de entrevistas, mas todas em formato aberto, apenas com o objetivo de "não usar as pessoas sem um propósito definido" (Booth, Colomb \& Williams, 2008, p. 93) e de forma a "separamos o que sabemos do que queremos saber [para] mais eficazmente encontrarmos aquilo que precisamos saber" (idem Booth, Colomb \& Williams, 2008, p. 93). Dessa forma, o protocolo inicial de entrevista foi constantemente ajustado e modificado, produzindo ao final um roteiro significativamente diferente ao final da pesquisa. As entrevistas precisam conter perguntas abertas para suspender, ao máximo possível, todas as opiniões e concepções prévias do pesquisador a respeito do objeto de pesquisa. O pesquisador deve, portanto, não ser diretivo ou limitar a autonomia dos participantes, implícita ou explicitamente, pois isso poderia impactar suas reações.

Documentos públicos oficiais constituíram o quarto grupo de fontes de análise. Estes documentos foram utilizados especialmente para analisar o processo legislativo da LAI e foram obtidos por meio de pedidos de acesso à informação. Alguns exemplos destes documentos públicos oficiais utilizados foram ofícios e pareceres jurídicos emitidos por órgãos envolvidos na elaboração da LAI; diferentes anteprojetos elaborados pela CGU; pareceres das consultorias jurídicas sobre pedidos de vetos à lei aprovada; atas das reuniões do Conselho para a Transparência. Como membro da organização que pesqui- 
sava, eu tinha acesso a documentos preparatórios, documentos não aprovados e portanto não publicados, dentre outros. Apesar de a condição de insider dar ao pesquisador acesso a essas informações, e apesar de a pesquisa qualitativa demandar a utilização do maior número de fontes possíveis, o pesquisador nativo deve limitar sua análise a documentos obtidos por vias oficiais, como pedidos de acesso à informação, ou documentos que se encontram publicamente disponíveis na internet. Esta é uma postura necessária, pois tanto a condição de pesquisador quanto a condição de membro da organização impõem o dever de resguardar documentos que não são públicos. Mesmo que isso acarrete eventual perda de profundidade para análise qualitativa de um processo decisório, a observância aos preceitos éticos de pesquisa requer do pesquisador uma preocupação com a autonomia dos participantes e com sua liberdade de não compartilhar documentos ou informações que não desejarem.

De qualquer forma, a utilização de diversas fontes de pesquisa aumenta a riqueza dos dados disponíveis e consequentemente a confiabilidade e a validade da análise. Afinal, isoladamente os quatro tipos de fontes desta pesquisa são limitados e não representam a realidade com precisão. A estrutura normativa do sistema, por exemplo, é mais um conjunto de enunciações normativas vagas do que um consenso rigoroso do conjunto de desejos de atores políticos. As entrevistas revelaram opiniões e percepções dotadas de um alto (e inevitável) grau de subjetividade, e fatores circunstanciais e imprevisiveis podem afetar as respostas dos participantes, que sempre devem ser lidas pelo pesquisador com ceticismo (Alvesson, 2003). As decisões sobre casos concretos também representam uma visão parcial da realidade, pois o registro de fatos e argumentos é uma decisão epistemológica sobre o que registrar e o que não registrar que muitas vezes exclui aspectos relevantes da controvérsia existente no caso (Farge, 2009). Porém, analisadas conjuntamente, com a devida triangulação, a interação destas diversas fontes permite um grau relevante de confiabilidade. Ademais, a triangulação, no caso da minha pesquisa, viabilizou um estudo com ao menos dois grandes níveis de análise: o nível mais amplo, referente à atuação das instituições de aplicação da LAI, e o nível mais restrito, focado nos indivíduos que operam o sistema de acesso à informação.

\subsection{Seleção de casos e coleta de dados: seus limites e o delineamento da pesquisa}

A seleção de casos é um dos maiores problemas da pesquisa qualitativa em geral e dos estudos de caso em particular. A seleção por meio da variável dependente (no meu caso, o resultado de recursos de acesso à informação) pode acarretar no enviesamento das conclusões quando os casos selecionados representam uma amostra truncada da variável independente (George \& Bennet, 2005) ou quando segue um procedimento conhecido como cherry-picking (Gerring, 2007), em que o pesquisador se engaja em uma "busca deliberada por evidência confirmatória", podendo incorrer em um viés de confirmação (Kahneman, 2012, p. 106). 0 enviesamento surge quando se selecionam casos que contêm apenas as variáveis independente e dependente que a teoria sugere estarem associados, desconsiderando assim casos que poderiam contradizer a teoria (George \& Bennet, 2005). Este primeiro perigo pode ser enfrentado com a seleção de 
casos polares, ou seja, casos que possuem a máxima variação possível na variável dependente (Gerring, 2007). No caso da minha pesquisa sobre transparência, analisei tanto casos em que o resultado do recurso de acesso à informação foi positivo (e consequentemente o órgão recursal disponibilizou a informação requerida) e casos em que o resultado foi negativo (e a informação requerida permaneceu sob restrição).

Mais do que casos polares (que não necessariamente contradizem a teoria proposta), é importante que o pesquisador analise em profundidade casos dissonantes. Afinal, na pesquisa qualitativa, casos que não se enquadram na teoria proposta não podem ser ignorados ou considerados meros "erros." Por isso, boa parte da pesquisa qualitativa, e em especial a pesquisa nativa, deve se dedicar a compreender os fatores que conduzem a um padrão sequencial distinto do esperado (Mahoney \& Goertz, 2006; Ragin, 2004).Os casos dissonantes ou negativos são aqueles em que o resultado a ser explicado poderia ter acontecido, mas não aconteceu, ou seja, casos em que estão presentes uma ou mais variáveis independentes associadas ao resultado, porém ele não se verificou. Casos dissonantes são frequentemente denominados de "anomalias" frente ao modelo teórico proposto. Contudo, eles somente são assim denominados porque não são suficientemente explicados, pois eles deixam de ser considerados outliers quando surge uma teoria que os explique adequadamente. De qualquer forma, a ênfase nestes casos é explicada pelo fato de que o estudo das anomalias é uma das melhores formas de promover o progresso científico (Gerring, 2007), pois casos que contradizem nossas ideias iniciais aumentam nossa exposição a novas ideias e contextos, abrindo novas possibilidades de teorização (Hibbert et al, 2014).
Na minha pesquisa, inicialmente escolhi os julgados analisados e as pessoas a serem entrevistadas por amostragem intencional. A partir da análise da estrutura normativa do sistema, selecionei alguns temas que me pareceram mais relevantes, o que me levou aos casos inovadores, que por sua vez me conduziram a uma primeira amostra de atores relevantes que mereciam ser entrevistados. Estes entrevistados me conduziram a outros, e a outros. Ou seja, apesar de o pesquisador nativo poder se valer, em um primeiro momento, de uma amostragem intencional, no desenvolvimento da pesquisa ele pode também adotar a amostragem do tipo bola de neve (snowball sampling), em que dados são coletados como uma forma de desdobramento dos casos previamente selecionados. Não houve tentativa de criar amostras aleatórias de entrevistados, e tampouco houve predeterminação de um número de entrevistas a serem realizadas. Acredito que o pesquisador qualitativo deve realizar entrevistas até que se sinta relativamente seguro de ter chegado ao ponto de saturação (Small, 2009), ou seja, ao ponto em que novas entrevistas não acrescentariam dados novos sobre o fenômeno de estudo. No caso da minha pesquisa, convidei 35 pessoas para a realização de entrevistas, das quais 25 aceitaram. Reforço, contudo, o entendimento de que não há um número mínimo certo ou sugerido de entrevistas. Nos casos em que obtive autorização, gravei e transcrevi as entrevistas. As transcrições foram feitas pessoalmente por mim e por uma colega, que assinou termo de compromisso de manutenção de sigilo. A técnica de transcrição pessoal de entrevistas, ainda que muito trabalhosa, pode propiciar frutos importantes ao pesquisador: ao realizar pessoalmente a transcrição, o pesquisador realiza ao mesmo tempo uma análise minu- 
ciosa da entrevista, não se atendo a pontos previamente selecionados como importantes, o que the permite perceber falhas ou pontos que podem ser aprofundados em entrevistas posteriores.

\section{Os desafios éticos da pesquisa no local de trabalho}

\subsection{Consentimento esclarecido e anonimato}

A minha dupla condição de pesquisador e de servidor público efetivo, com quatro anos de exercício anteriores à realização da pesquisa no órgão que foi o principal objeto da minha pesquisa, impôs problemas éticos difíceis de serem solucionados. Para evitar o "duplo prejuízo" (Yin, 2016) que a pesquisa nativa pode acarretar, mantive um código ético rigoroso durante a realização da pesquisa. Em primeiro lugar, minha condição de servidor público impôs a necessidade de observar uma série de regras, em especial as que constam no art. 116 da Lei n. 8.112/90 (Brasil, 1990), como "guardar sigilo sobre assunto da repartição" e "manter conduta compatível com a moralidade administrativa". Dessa forma, apesar de ter tido acesso, como servidor público, até mesmo a documentos em estágio de preparação, a informações não publicadas e a conversas informais, não pude, por dever legal, revelá -las sem consentimento dos envolvidos ou sem autorização expressa dos meus superiores hierárquicos. Assim, ainda que uma pesquisa de enfoque qualitativo tudo que o pesquisador vê, ouve ou the é comunicado deva ser considerado como dado de pesquisa (Maxwell, 2013), os dados obtidos na pesquisa nativa devem provir apenas das quatro fontes a que me referi anteriormente.

Com relação às entrevistas, o pesquisador nativo precisa explicar aos participantes que a sua participação é totalmente voluntária, sendo que eles podem se recusar a responder algumas ou todas as perguntas. É importante também esclarecer ao entrevistado se sua participação será considerada institucional ou individual: no primeiro caso, é preciso obter um aceite institucional, enquanto que no segundo o aceite institucional é desnecessário ou até mesmo indesejável, já que a ele, além de em nada contribuir para o objetivo de pesquisa, pode expor desnecessariamente os participantes, podendo assim criar vieses, pois quanto mais expostos se sentirem os participantes, maiores as chances de que eles se sentissem constrangidos a não demonstrar divergências ou opiniões contrastantes com as posições oficiais. Além de expor os participantes indevidamente, obter um aceite institucional em casos de participação individual pode fazer com que os participantes desconfiem que o pesquisador representa os interesses dos superiores, o que pode enviesar suas respostas e sua participação (Williams, 2006). Essas "associações implícitas" devem ser evitadas porque "os funcionários podem responder de maneira diferente caso acreditem que um estudo foi sancionado por seu empregador" (Yin, 2016, pp. 103-104).

O pesquisador precisa informar os participantes acerca dos riscos envolvidos na realização da pesquisa, para que eles tenham condições de analisar a conveniência de sua participação. No caso da minha pesquisa de doutorado, informei os participantes que a pesquisa envolvia um risco relevante. As informações reveladas poderiam expô-los aos seus colegas de profissão e à sua instituição, no caso de serem reveladas opiniões porventura polêmicas a respeito deles ou 
do funcionamento da instituição pesquisada, o que poderia ter consequências sobre suas trajetórias profissionais, direta ou indiretamente. No caso da minha pesquisa, esse problema foi minimizado porque os participantes da pesquisa possuíam condições de estarem plenamente cientes destes riscos, devido ao seu alto nível educacional: os entrevistados eram auditores, ouvidores, acadêmicos, ocupantes de cargos comissionados de alto nível na administração pública. No entanto, estes riscos são relevantes se participarem da pesquisa pessoas em condição de vulnerabilidade, definidas como as que "tenham a sua capacidade de autodeterminação reduzida ou impedida" (Brasil, 2012, II. 25), como crianças, adolescentes, presos, hipossuficientes. O pesquisador sempre deve fornecer aos participantes um Termo de Consentimento Livre Esclarecido em linguagem adequada ao contexto e que efetivamente informe os participantes acerca das características principais da pesquisa. Além disso, é dever do pesquisador adotar medidas para minimizar os riscos da pesquisa. Tendo em vista ser o anonimato a forma mais comum de proteção aos participantes, sugeri na minha pesquisa que os entrevistados optassem por não terem seus nomes publicados. Sugeri também que nos encontrássemos fora de seu ambiente de trabalho, de modo a preservar a discrição e permitir que nossa conversa se desse da forma mais livre possível. $\mathrm{Na}$ transcrição das entrevistas anônimas, padronizei declinações de gênero (no masculino) e de tempo (no passado), para evitar identificações indiretas.

No entanto, no caso da pesquisa nativa, ser colega dos participantes muitas vezes torna o anonimato uma forma insuficiente de proteção. Afinal, é possível que alguns dos participantes se sintam expostos pelo simples fato de revelar informações ao seu colega de trabalho, mesmo que ninguém mais além do pesquisador/colega saiba da proveniência daquela informação. Assim, considerando que a natureza das relações entre pesquisador e participante afeta a qualidade da produção de dados (Hall \& Callery, 2001; Popay et al, 1998), o pesquisador nativo precisa adotar procedimentos adicionais de proteção aos participantes. No caso da minha pesquisa, adotei a "técnica da urna" (Diniz \& Medeiros, 2010) para indagar os participantes sobre questões que considerei sensíveis. Pedi-os que respondessem a algumas perguntas por escrito, sem identificação. Os entrevistados que aceitaram participar desta parte da entrevista depositaram o questionário preenchido em uma urna que foi mantida trancada durante o período de coleta de entrevistas, sendo que a chave ficou sob posse do primeiro participante. Dessa forma, nessas perguntas, nem mesmo eu, como entrevistador e autor da pesquisa, saberia o autor de cada resposta individual. Após a realização de entrevistas, me encontrei novamente com o primeiro participante, que me devolveu a chave, sem ter acesso à urna nessa ocasião. As respostas contidas na urna possuíram validade limitada: ao mesmo tempo em que não tinham a profundidade de uma entrevista pessoal, tampouco possuem força estatística, pois a amostra de entrevistados foi pequena e não aleatória. Apesar disso, as respostas serviram como indícios de questões que porventura não foram abordadas nas entrevistas mas que mereciam aprofundamento analítico posterior.

A ênfase no anonimato - e no anonimato efetivo, e não meramente formal - é importante não apenas por se tratar de cuidado 
ético amplamente reconhecido como a principal forma de proteger participantes em pesquisas acadêmicas, mas também porque ele exerce outras funções, relacionadas à ontologia da pesquisa, ao seu caráter analítico e, também, à independência do pesquisador (Vainio, 2012). Ontologicamente, o anonimato empodera os participantes de pesquisa, que sob segredo adquirem maior liberdade para se expressar e emitir opiniões eventualmente desfavoráveis à instituição de que fazem parte. Analiticamente, o anonimato permite que o pesquisador e os leitores se foquem no que foi dito e não em que o falou, eliminando informações irrelevantes para os objetivos de pesquisa. Assim, o anonimato viabiliza o deslocamento do foco do individual para o abstrato, permitindo a teorização e generalização dos achados de pesquisa. Por fim, o anonimato permite uma maior independência por parte do pesquisador, que pode se sentir mais livre para expor tanto posições favoráveis quanto desfavoráveis aos participantes, já que a crítica deixará de ser individual. Em suma, a "forma com que o anonimato é tratado e aplicado tem importantes consequências e modifica a função do pesquisador e dos participantes da pesquisa, a lógica da análise e a percepção de imparcialidade dos resultados" (Vainio, 2012, p. 695).

Apesar do amplo suporte existente na literatura acerca da importância do anonimato como ferramenta ética e metodológica, há autores que argumentam que o anonimato, ao proteger o segredo, compromete a produção de conhecimento, impede mudanças nas relações políticas e torna invisíveis arranjos de opressão, minimizando o engajamento do pesquisador e dos respondentes em processos de transformação social (Baez, 2002). Segundo este argumento, pesquisadores adotam o anonimato irrefletidamente, sem perceber que seu uso está atrelado a um contexto político que sobrevaloriza a privacidade individual em detrimento de outras funções sociais que podem ser mais relevantes para uma pesquisa, como o combate a estruturas hegemônicas de poder. Nespor (2000) também questiona a efetividade do anonimato como forma de proteção, argumentando que é impossível esconder plenamente a identidade dos participantes, a não ser que se retirem da pesquisa as suas informações mais fundamentais, aquelas que tornam único e relevante o objeto estudado. O autor argumenta que o anonimato abstrai o objeto de pesquisa ao custo de descontextualizá-lo de seu contexto político e histórico, promovendo uma espécie de privatização das pesquisas científicas, pois o pesquisador passa a ser hegemônico ao delimitar o que deve e o que não deve ser publicado sem que haja qualquer controle sobre isso.

Considerando esse contraste de visões, talvez a melhor solução seja compartilhar a decisão a respeito do anonimato com os participantes. No caso da minha pesquisa, ainda que eu tenha seguido a prática geral de sugerir o anonimato, dei a todos os participantes a opção de terem seus nomes mencionados na pesquisa. Afinal, o pesquisador também tem a obrigação de respeitar a autonomia dos participantes, que devem ter a opção de livremente compartilhar informações (Bok, 1986) e de receber reconhecimento por suas palavras, opiniões e histórias (Grinyer, 2002). Adotei assim uma forma mitigada ou revogável de anonimato, a despeito de existirem pesquisadores que discordam da visão de que os participantes devam ter individualmente a opção de permanecer anônimos ou não. É o caso 
de Giordano et al (2007), que afirmam que uma pesquisa acadêmica deve maximizar a produção de informações confiáveis, mesmo que isso limite a autonomia dos participantes em decidir sobre o anonimato; e que o reconhecimento da voz dos participantes deve se dar no âmbito coletivo, e não individualmente. Para estes pesquisadores, abrir mão do anonimato pode afetar os resultados da pesquisa, e, portanto, o pesquisador não deve dar esta opção aos participantes. $\mathrm{Na}$ minha pesquisa, contudo, dei individualmente aos participantes a possibilidade de se identificarem, por acreditar que, por seu alto nível de instrução, eles teriam plenas condições de avaliar (até melhor do que eu) os riscos a que se submeteriam ao compartilhar informações e, também, por acreditar que a opção pelo não anonimato de um participante em nada afetaria ou prejudicaria a opção do anonimato dos outros. Em se tratando de pesquisa com pessoas em estado de vulnerabilidade, contudo, a melhor opção possivelmente é aquela que privilegia o anonimato independentemente do consentimento dos participantes.

\subsection{Validação do respondente e pesquisa colaborativa}

O anonimato, mesmo em sua forma absoluta, não elimina todos os riscos da pesquisa. Isso porque, dependendo da forma com que as informações são escritas e analisadas, pode ser possível a identificação indireta da pessoa que a revelou. Nestes casos o anonimato pode ter efeitos contrários aos pretendidos, na medida em que a "confidencialidade pode dar aos pesquisadores o sentimento de proteção completa quando, na verdade, ela frequentemente ainda dei- xa os respondentes vulneráveis a identificação e a possíveis riscos" (Guenther, 2009, p. 413). Esse problema é aumentado na medida em que o pesquisador nativo muitas vezes não consegue perceber as pistas que podem levar à identificação indireta dos participantes, tendo em vista que os conhece individualmente. Por isso, o pesquisador nativo deve dar aos entrevistados a possibilidade de avaliar uma versão preliminar do seu trabalho antes de sua publicação definitiva. Isso Ihes dá a oportunidade de verificar se a versão final permite a sua identificação indireta, ou mesmo se houve algum tipo de má-interpretação de falas, comportamentos ou respostas escritas. Isso não apenas oportuniza aos participantes revisar os argumentos, pressupostos e marcos teóricos do trabalho, mas também lhes dá a chance de retratar, parcial ou totalmente, as suas falas, e também de rever seu posicionamento quanto ao anonimato.

A estratégia de dialogar com os participantes e permitir a sua retratação impõe custosà pesquisa, que deverá descartar dados quando houver risco aos participantes (Guenther, 2009). No entanto, trabalhar de forma coordenada com os participantes também traz benefícios relevantes. Assim, enviar o texto preliminar para conferência dos participantes não é apenas um cuidado ético voltado a aumentar os laços de cooperação com os participantes, mas também uma estratégia metodológica voltada a aumentar a confiabilidade dos achados de pesquisa por meio da validação do respondente (Yin, 2016; Locke; Velarumi, 2009), que é a forma "mais importante de excluir a possibilidade de má interpretação sobre o significado do que os participantes falam e fazem e das perspectivas que eles têm sobre o que está aconte- 
cendo." (Maxwell, 2013, p. 116). É, em suma, uma forma de falar com os participantes, em vez de simplesmente falar para eles (Alcoff, 1992; Hibbert et al, Kempster \& Stewart, 2010; Marcos \& Denyer, 2012), de maneira a reconhecer que nossas posições de fala como pesquisadores são epistemologicamente relevantes e podem influenciar os resultados da pesquisa (Alcoff, 1992).

Valorizar as relações com os participantes permite a exposição do pesquisador a "novos contextos, ideias e novas possibilidades de teorização" (Hibbert et al, 2014, p. 283284), viabilizando o "engajamento com a alteridade" (engaging otherness), que significa "explorar diferenças como uma forma de romper as barreiras e abrir a conversa a novas vozes e conectar-se, desenvolvimento novas construções relacionais em relação à nossa comunidade, dados e contextos de pesquisa" (Hibbert et al, 2014, p. 284). Esta atividade não é fácil e, em alguns momentos excepcionais, pode não ser particularmente agradável ou prazerosa. No meu caso, alguns participantes, como membros das instituições que pesquiso, demonstraram discordâncias fortes com a minha pesquisa, o que me fez ouvir críticas duras. De qualquer forma, a atividade foi recompensadora, pois permitiu o enfrentamento de teorias e formas de pensar alternativas, contribuindo para superar o fechamento e isolamento de minha própria comunidade de conhecimento e para estabelecer uma conexão diferenciada com meus dados de pesquisa, de forma a compreender a sua ambiguidade e complexidade. Em suma, "por meio do engajamento com a alteridade e da conexão com diferentes comunidades, adicionamos largura à nossa profundidade interpretativa" (Hibbert et al, 2014, p. 291).

Por outros termos, mais do que simples- mente absorver informações dos participantes, o pesquisador nativo precisa dialogar com eles e tentar ao máximo reconhecê-los e engajá-los como coprodutores da pesquisa, e não como meros objetos. Ele precisa, na linguagem técnica da literatura, trabaIhar com eles nos espaços de conexão ou hyphen spaces (Cunliffe \& Karunayake, 2013; Fine, 1994; Baghan, 2008; Wagle \& Cantaffa, 2008), que enfatizam "não as fronteiras, mas sim os espaços de possibilidade entre pesquisadores e respondentes" (Cunliffe \& Karunayake, 2013; p. 365). Isso envolve reconhecer a existência de uma mútua e múltipla influência entre pesquisador e participantes. Ou seja, os hyphen spaces envolvem "examinar reflexivamente como a nossa presença influencia e/ou muda as pessoas e suas práticas e como a presença delas nos influencia, intencionalmente ou não, revestindo as relações de identidade que podem ocorrer entre nós e nossos participantes de pesquisa (...), bem como examinar as implicações [desta mútua influência] para a prática da pesquisa" (Cunliffe \& Karunayake, 2013; p. 365). Quando o pesquisador tem por objeto seu próprio ambiente de trabalho, suas relações com muitos dos participantes é mais complexa e interconectada do que uma simples e facilmente divisível relação pesquisador/respondente: por vezes essa relação é mediada por vínculos de amizade, subordinação ou hierárquica; por vezes o nativo é visto como um insider, por vezes como um outsider; por vezes o nativo é reconhecido como alguém semelhante aos colegas, por vezes não.

\subsection{Aprovação do Comitê de Ética em Pes- quisa}

O Brasil possui um sistema de revisão de éti- 
ca em pesquisa constituído pelos Sistemas de Comitês de Ética em Pesquisa (CEP) da Comissão Nacional de Ética em Pesquisa (CONEP). Esse sistema de comitês de ética não é regulamentado por lei, mas sim pelas Resoluções $n^{\circ}$ 466/2012 e 510/2016 do Consenho Nacional de Saúde (CNS). O objetivo principal do sistema é a proteção aos participantes de pesquisa, e por isso as resoluções do CNS partem da presunção de que toda e qualquer pesquisa envolvendo seres humanos pode acarretar riscos aos participantes, envolvendo, portanto, a necessidade de revisão ética. O sistema de comitês de ética tem sua origem ligada ao campo da saúde, e até hoje é regulamentado e dominado por esse campo. Por isso, existem poucos comitês de ética especificamente associados à área de ciências humanas e sociais, sendo o Comitê de Ciências Humanas e Sociais da UnB uma exceção a essa regra, De qualquer forma, pesquisas nas áreas de ciências sociais aplicadas também podem acarretar riscos relevantes aos participantes da pesquisa, e por isso as regras gerais sobre cuidados éticos também devem ser observadas nesta área, especialmente quando se trata de pesquisa nativa.

A submissão do projeto de pesquisa por meio da plataforma brasil, portanto, deve obedecer os seguintes princípios e regras inseridos nas resoluções do Conselho Nacional de Saúde: deve-se respeitar a autonomia dos participantes, o que é feito por meio da sua adesão à pesquisa por meio de assentimento livre e esclarecido, que é um consentimento qualificado pelo fato de constituir "um sinal do verdadeiro significado do pacto de consentimento que um indivíduo assina ao ser incluído na pesquisa" (Diniz \& Guilhem, 2014, p.48) e que envolve o direito do participante de ser informado e compreender plenamente a natureza, os objetivos e os métodos da pesquisa, bem como a sua liberdade plena em decidir sobre sua participação na pesquisa ou sobre sua possibilidade de interrupção; deve haver um compromisso por parte do pesquisador de sopesar os benefícios sociais que a pesquisa gerará com seus potenciais riscos, aos quais o pesquisador deverá estar sempre atento e que deverão ser entendidos em um sentido amplo como envolvendo "possibilidade de danos à dimensão física, psíquica, moral, intelectual, social, cultural do ser humano, em qualquer etapa da pesquisa e dela decorrente" (Brasil, 2016, art. $2^{\circ}, \mathrm{XXV}$ ); deve haver garantia de proteção das informações pessoais dos participantes de pesquisa (Brasil, 2011, art. 31; B, 2016, art. $2^{\circ}$, VII); deve-se também garantir acesso aos participantes dos resultados da pesquisa (Brasil, 2016, art. 17, VI).

\section{Conclusões}

Juristas frequentemente realizam pesquisas qualitativas que combinam a expertise prática com ferramentas acadêmicas. Esta combinação de abordagens profissional e acadêmica pode gerar resultados poderosos, mas esta forma de fazer pesquisa envolve a necessidade de adoção de cuidados metodológicos e éticos.Este artigo buscou demonstrar as estratégias que adotei para minimizar vieses na minha pesquisa de doutorado sobre a aplicação da Lei de Acesso à Informação na Controladoria-Geral da União: a reflexividade, a triangulação, a análise de casos que contradiziam minha hipótese inicial de pesquisa, e a adoção de cuidados éticos tais como o anonimato e a validação do respondente. É importante que estas e outras estratégias de redução de vieses sejam discutidos em pesquisas jurídicas, 
que via de regra se preocupam insuficientemente com questões metodológicas ou éticas e refletem pouco sobre como elas podem influenciar os resultados de pesquisas acadêmicas. À medida em que o Direito se torna, gradualmente, uma ciência, baseando suas conclusões em constatações empíricas que, senão neutras, devem ser confiáveis, campo precisa começar a se preocupar em incorporar às suas análises ferramentas metodológicas validadas em outras áreas do conhecimento.

\section{Referências}

ALCOFF, Linda (1992). The Problem of Speaking for Others. Cultural Critique, $n^{\circ}$. 20, pp. 5-32.

ALISSON, Graham; ZELIKOW, Philip (1999). Essence of Decision: Explaining the Cuban Missile Crisis. New York: Addison Wesley Longman.

ANDERSON, Gary L.; HERR, Kahryn (1999). The new paradigm wars: Is there room for rigorous practitioner knowledge in schools and universities? Educational Researcher, 28, 12-21, 40

AVLESSON, Mats (2003). Methodology for close up studies - struggling with closeness and closure. Higher Education, v. 46, 167-193.

BAEZ, Benjamin (2002). Confidentiality in qualitative research: reflections on secrets, power and agency. Qualitative Research, v. 2(1):35-58.

BOK, S (1983). The limits of confidentiality. Hastings Center Report, 13(1): 24-31.

BOOTH, Wayne C; COLOMB, Gregory G.; WILLIAMS Joseph M. A Arte da Pesquisa (2008). Tradução Henrique A. Rego Monteiro. São Paulo: Martins Fontes.

BECKER, Howard S. Whose Side Are We On? Social Problems, v. 14, n. 3, p. 239-247, 1967.BOURDIEU, Pierre (2004). Science of Science and Reflexivity. Chicago: Polity Press and the University of Chicago.

BRANNICK, Teresa, COGHLAN, David (2007). In defense of being native: the case for insider academic research. Organizational research methods, 10, pp. 59-74. (2005). Doing Action Research in your own Organization. London, Thousand Oaks and New Delli: Sage Publications.

BRASIL. Lei n. 12.527, de 18 de novembro de 2011. Regula o acesso a informações previsto no inciso XXXIII do art. $5^{\circ}$, no inciso II do § 30 do art. 37 e no § 20 do art. 216 da Constituição Federal; altera a Lei n 8.112, de 11 de dezembro de 1990; revoga a Lei $n^{\circ} 11.111$, de 5 de maio de 2005, e dispositivos da Lei $n^{\circ} 8.159$, de 8 de janeiro de 1991; e dá outras providências. Diário Oficial da União, 18 nov. 2011.

Conselho Nacional de Saúde do Ministério da Saúde. Resolução n. 466, de 12 de Dezembro de 2012. Diário Oficial da União 12 Dez 2012

Conselho Nacional de Saúde do Ministério da Saúde. Resolução n. 510, de 10 de Abril de 2016. Diário Oficial da União 10 abr 2016.

CUNHA FILHO, Marcio C (2018). O que Sabemos sobre Transparência Pública? Uma revisão bibliográfica das abordagens normativa, conceitualista e empírica. Revista da CGU, v. 10, n. 16

(2019). A Construção da Transparência Pública no Brasil: Análise da Elaboração e Implementação da Lei de Acesso à Informação no Executivo Federal (2003-2019). Tese (Doutorado em Direito). Brasília, Universidade de Brasília.

CUNLIFFE, Ann L. (2011). Crafting qualitative research: Morgan and Smircich 30 years on. Organizational Research Methods, 14, 647-673.

CUNLIFFE, Ann L.; KARUNANAYAKE, Geetha (2013. Working within hyphen-spaces in ethnographic research: Implications for research identities and practice. Organizational Research Methods, 16, 364-392, 2013.

DINIZ, Debora; GUILHEM, Dirce (2014). O que é Ética em Pesquisa. Brasília, Editora Brasiliense.

DINIZ, Debora and MEDEIROS, Marcelo. Aborto no Brasil: uma pesquisa domiciliar com técnica de urna. Ciência. saúde coletiva [online], 2010, vol.15, pp.959-966

FARGE, Arlette (2009). O sabor do arquivo. Trad. Fátima Murad. São Paulo: Editora da Universidade de São Paulo.

GEORGE, Alexander L; BENNET, Andrew (2005). Studies and Theory Development in the Social Sciences. Cambridge: MIT Press.

GERRING, John (2007). Case Study Research: Principles and Practices. New York: Cambridge University Press.

(2004). What is a Case Study and What is It Good for? American Political Science Review, 98 (2): 341-354.

GRINYER, Anne (2002). The anonymity of research participants: assumptions, ethics and practicalities. Social Research Update 36, University of Surrey, UK. 
GUENTHER, Katja M (2009). The politics of names: rethinking the methodological and ethical significance of naming people, organizations, and places. Qualitative Research; 9(4):411-421.

JACOBS, Alan. Policymaking as political constraint: institutional development in the U.S. Social Security Program. In: MAHONEY, James; THELEN, Kathleen (ed.). Explaining Institutional Change: Ambiguity, Agency and Power. New York: Cambridge University Press, 2010.KAHNEMAN, Daniel (2012). Rápido e Devagar: duas formas de pensar. Trad. Cássio Leite. Rio de Janeiro: Objetiva.

LYNCH, Michael (2000). Against reflexivity as an academic virtue and source of privileged knowledge. Theory, Culture \& Society, vol 17, 3: 26 - 54.

MAHONEY, James, GOERTZ, Gary (2006). A Tale of Two Cultures: Contrasting Quantitative and Qualitative Research. Political Analysis, v. 14: 227-249.

(2004). The possibility principle and case selection: choosing negative cases in comparative anaysis. The American Political Science Review, vol. 98, $\mathrm{n}^{\circ} 4$ : 653-669.

MARCOS, Javier \& DENYER, David (2012). Crossing the sea from they to we? The unfolding of knowing and practicing in collaborative research. Management Learning, 43(4): 443-459.

MAXWELL, Joseph A (1996). Qualitative research design: an interactive approach. Thousand Oaks: Sage.

MCINTYRE, Lee (2019). The Scientific Attitude: Defending Science from Denial, Fraud and Pseudoscience. Cambridge, MIT Press.

MUNRO, Geoffrey D.; DITTO, Peter H (1997). Biased assimilation, attitude polarization, and affect in reactions to stereotype-relevant scientific information. Personality and Social Psychology Bulletin, 23 (6): 636 653.

NESPOR, Jan (2000). Anonymity and place in qualitative inquiry. Qualitative Inquiry 6(4): 546-569.

POPAY, Jennie, ROGERS, Anne, \& WILLIAMS, Gareth (1998). Rationale and standards for the systematic review of qualitative literature in health sciences research. Qualitative Health Research, 8, 341.

RAGIN, Charles C (2004). "Turning the Tables." In: BRADY, Henry; COLLIER, David (eds.). Rethinking Social Inquiry: Diverse Tools, Shared Standards. Lanham: Rowman \& Littlefield) 123-38.

SAID, Edward (2005). Representações do intelectual: as conferências Reith de 1993. Trad. Milton Hatoum. São Paulo: Cia das Letras.
SMALL, Mario Luis (2009). How many cases do I need? On science and the logic of case selection in field-based research. Ethnography, vol 10 (1): 5 - 38.

VAINIO, Annukka (2012). Beyond research ethics: anonymity as "ontology", "analysis" and "independence". Qualitative Research, 13(6): 685-698.

WAGLE, Tina \& CANTAFFA, David $T$ (2008). Working our hyphens: Exploring identity relations in qualitative research. Qualitative Inquiry, 14(1): 135-159.

WILLIAMS, Christine (2006). Inside toyland: working, shopping and social inequality. Berkeley: University of California Press.

YIN, Robert (2016). Pesquisa qualitativa: do início ao fim. Trad. Daniel Bueno. Porto Alegre: Penso.

Data de submissão: 13/01/2019 Data de aceite: 19/07/2019 